\title{
Implementing infrastructures for managing learning objects
}

Citation for published version (APA):

Klemke, R., Ternier, S., Kalz, M., \& Specht, M. M. (2010). Implementing infrastructures for managing learning objects. British Journal of Educational Technology, 41(6), 873-882. https://doi.org/10.1111/j.1467-

8535.2010.01127.x

DOI:

10.1111/j.1467-8535.2010.01127.x

Document status and date:

Published: 01/11/2010

Document Version:

Peer reviewed version

Document license:

CC BY-NC-ND

Please check the document version of this publication:

- A submitted manuscript is the version of the article upon submission and before peer-review. There can be important differences between the submitted version and the official published version of record. People interested in the research are advised to contact the author for the final version of the publication, or visit the DOI to the publisher's website.

- The final author version and the galley proof are versions of the publication after peer review.

- The final published version features the final layout of the paper including the volume, issue and page numbers.

Link to publication

\section{General rights}

Copyright and moral rights for the publications made accessible in the public portal are retained by the authors and/or other copyright owners and it is a condition of accessing publications that users recognise and abide by the legal requirements associated with these rights.

- Users may download and print one copy of any publication from the public portal for the purpose of private study or research.

- You may not further distribute the material or use it for any profit-making activity or commercial gain

- You may freely distribute the URL identifying the publication in the public portal.

If the publication is distributed under the terms of Article 25fa of the Dutch Copyright Act, indicated by the "Taverne" license above, please follow below link for the End User Agreement:

https://www.ou.nl/taverne-agreement

Take down policy

If you believe that this document breaches copyright please contact us at:

pure-support@ou.nl

providing details and we will investigate your claim.

Downloaded from https://research.ou.nl/ on date: 26 Apr. 2023 
PREPRINT Klemke, R., Ternier, S., Kalz, M. \& Specht, M. (2010). Implementing infrastructures for managing learning objects. British Journal of Educational Technology

\title{
Implementing infrastructures for managing learning objects
}

\author{
Roland Klemke, Stefaan Ternier, Marco Kalz and Marcus Specht \\ Roland Klemke, Stefaan Ternier, Marco Kalz and Marcus Specht are members of the \\ learning media research programme of the Centre for Learning Sciences and \\ Technologies (CELSTEC) of the Open Universiteit Nederland. Roland Klemke is \\ Assistant Professor at CELSTEC and CEO of Humance AG (Germany). His research \\ interests comprise content development, reuse and ubiquituous use. Stefaan Ternier \\ is Assistant Professor at CELSTEC. His research interests are in architectures for \\ learning objects and interoperability. Marco Kalz is Assistant Professor at CELSTEC. \\ His research focus is on new forms of assessment and the use of social software and \\ open educational resources for lifelong competence development. Marcus Specht is \\ Full Professor at CELSTEC. His research interests are adaptive learning and training \\ systems, knowledge management, contextualized computing, and intelligent \\ interfaces. Address for correspondence: Roland Klemke, Center for Learning Sciences \\ and Technologies (CELSTEC), Open Universiteit Nederland, P. O. Box 2960, 6401 DL \\ Heerlen, The Netherlands. Email: roland.klemke@ou.nl
}

\begin{abstract}
Making learning objects available is critical to reuse learning resources. Making content transparently available and providing added value to different stakeholders is among the goals of the European Commission's eContentPlus programme. This article analyses standards and protocols relevant for making learning objects accessible in distributed data provider networks. Types of metadata associated with learning objects and methods for metadata generation are discussed. Experiences from European projects highlight problems in implementing infrastructures and mapping metadata types into common application profiles. The use of learning contents and its associated metadata in different scenarios is described and concluded with lessons learned and pitfalls to avoid.
\end{abstract}

\section{Introduction}

For nearly two decades, learning objects have been actively developed, published and disseminated. Research focused on standardising metadata, resulting in standards like Learning Object Metadata (LOM) and Dublin Core (DC) (Weibel et al, 1998). The Learning Technology Standards Committee of the Institute of Electrical and Electronics Engineers proposed the LOM standard to the public (IEEE LTSC, 2002). Repositories for learning object have been implemented for universities, disciplines or countries. Their increasing number and size complicated the search for relevant learning content for end-users. It became evident, that uniform access to distributed repositories is important.

The European commission's eContentplus programme aims to make digital content in Europe accessible, usable and exploitable. Projects in domains like geography, education and digital libraries were funded. We discuss in this article pitfalls and lessons learned from several projects, looking at distributed content mangagement, content federation infrastructures, metadata classes and generation and practical aspects of distributed learning object repositories: 
PREPRINT Klemke, R., Ternier, S., Kalz, M. \& Specht, M. (2010). Implementing infrastructures for managing learning objects. British Journal of Educational Technology

- Metadata for Architectural Contents in Europe (MACE) connects architectural repositories and enriches their contents with metadata (social metadata, geographical metadata, etc.)

- Interoperable Content in a Competency-driven Society (ICOPER) promises over 12.500 hours of distributed educational content

- Sharing Digital Resources in the Teaching Education Community (Share.TEC) fosters digital culture in the Teacher Educator community

- A metadata ecology for learning and Teaching (MELT) focuses on exchanging learning resources in schools

- Skill based scouting of open user-generated and community-improved content for management education and training (OpenScout) targets userfriendly access to management education content

\section{Distributed content management}

Relevant activities for distributed content management are reading, writing, and searching, while a critical factor is the availability of metadata. Service proposals for distributed metadata management infrastructures exist. The E-Learning Framework (Wilson, Blinco, \& Rehak, 2004) specifies classes of elearning services, amongst which are services for content management (archiving, digital rights management, metadata management, federated search, etc). Relevant functions for distributed metadata management are:

1. Read. Enable third party "service providers" to access metadata, using protocols like Really Simple Syndication (RSS, http://www.rssboard.org/rssspecification) or the Open Archive Initiative's Protocol for Metadata Harvesting (OAI-PMH) (Lagoze and van de Sompel, 2001).

2. Query. Protocols and APIs to browse or search content. (Simon et al, 2005)

3. Write. Enable applications (e.g. authoring environments) to submit resources to repositories.

The open archives initiative's protocol for metadata harvesting (OAI-PMH) enables harvesting metadata available in repositories. Using local metadata-caches, service providers can build search engines over metadata of multiple harvested repositories. OAI-PMH can be compared to RSS and atom feeds enabling client applications to download metadata entries but adds selective harvesting (e.g. harvest only things that were modified within a given datespan) and flow control (allow batched retrieval of metadata instances using resumption tokens).

Several specifications for publishing resources or metadata to repositories exist:

- The Simple Publishing Interface (SPI) (Ternier et al, 2009) allows publishing with bindings. E.g. a REST (Fielding, 2000) based binding exists for SPI that is compatible with Atom Publishing Protocol.

- Simple Webservice Offering Repository Deposit (SWORD, http://swordapp.org/) extends the Atom Publishing Protocol, enabling content publishing to repositories.

- Package Exchange Notification Services (PENS, http://www.aicc.org/docs/AGRs/agr011v1.pdf) is a notification service developed by the Aviation Industry CBT Committee (AICC), which can publish content packages to a learning management system (LMS). It specifies how an LMS can notify package processing. 
PREPRINT Klemke, R., Ternier, S., Kalz, M. \& Specht, M. (2010). Implementing infrastructures for managing learning objects. British Journal of Educational Technology

The Alliance of Remote Instructional Authoring and Distribution Networks for Europe (ARIADNE) developed an API to query learning objects within ARIADNE repositories from outside (Ternier et al., 2009). Similarly, European schoolnet developed a search API based on Java Messaging Service (Simon et al, 2005). Edutella (Nejdl et al, 2002) and LOMster (Ternier et al., 2002) wrap educational repositories in peer-2peer networks. This work was brought to the European Committee for Standardization, Information Society Standardization System (CEN/ISSS) for harmonisation resulting in the Simple Query Interface (SQI). Since then, SQI was widely implemented and supports repository federations (e.g. GLOBE network, http://www.globe-info.org/).

Query (SQI) and Read (OAI-PMH) are complementary functions to transparently search repositories. Search and read protocols facilitate (meta)data retrieval. Write protocols help to upload resources or metadata to repositories. Enabling an authoring application to directly publish a resource into a repository lowers the boundary of making the resource available for search and reuse. This optimises the user's workflow and enables automatic metadata generation: the authoring environment knows resource title, author, MIME-type, etc.

\section{Infrastructures for content federation}

A repository federation requires software architecture and metadata model. Metadata models differ between domains. Metadata describing e.g. architectural knowledge about buildings differs from metadata for school resources. Teachers often use search parameters like suitable age range of a resource, while in architecture mapbased search tools require GPS coordinates. Consequently, metadata models are tailored and sometimes specific software tools are required.

The process of setting up a distributed network comprises four phases:

1. Analyse existing repositories and their metadata, create a metadata application profile (MAP), and identify (or create) domain taxonomies (Hunter, 2003). As the creation of new classifications complicates interoperability, create a MAP using existing metadata and metadata standards. Reusing standards enable federations to interoperate with each other. The MACE MAP is based on existing architectural taxonomies while the broader ICOPER MAP does not utilize taxonomies at all.

2. Implement the MAP and provide mappings from different metadata schemas into it. A mapping may simply involve exposing the resource title as LOM title, but it may also explicate implicit metadata: the Dutch repository OpenER (http://opener.ou.nl) does not document that its content is in Dutch. Within the ICOPER federation, this information is relevant.

3. Validate metadata. As the metadata is published to a federation, validation ensures conformity to the rules of the MAP. MACE, MELT and ICOPER use the Ariadne validation service (http://ariadne.cs.kuleuven.be/validationService/) for this.

4. Once content and metadata are available, start implementing the federation and populate the search engine with metadata instances.

These steps are not strictly sequential. However, a change in the MAP results in updating the mappings for the different repositories (and not in updating the original metadata in the repositories). 
PREPRINT Klemke, R., Ternier, S., Kalz, M. \& Specht, M. (2010). Implementing infrastructures for managing learning objects. British Journal of Educational Technology

A content federation architecture divides software system and responsibilities. With the specifications outlined previously, an architecture for content federation can be realized using existing software components:

- Repositories can offer content and metadata to the federation through the implementation of an OAI-PMH target. OAI-PMH separates responsibilities: The repository behind the OAI-PMH interface is responsible for managing content and metadata and exporting it compliant to the federation's MAP. The federation middleware is responsible for making the metadata searchable, but not for managing the metadata or presenting the search results to end user.

- Search applications are connected to the federation middleware through a search API. This API again separates the responsibility of presenting an application to the end user from the responsibility of executing queries on search engines.

- Usage scenarios and appropriate user interfaces are important for federated content repositories. Within the proposed archtecture user interfaces can be developed independently from the backend architecture.

Carefully dividing these responsibilities enables reuse of software components, lowering the cost of implementing a content federation. Indeed, Share.TEC, MACE, MELT and ICOPER share reused software components.

\section{Classes of Metadata}

Metadata is often informally defined as "data about data". It, however, not only describes data: Hunter (2003) defines metadata as "the value-added information which documents [...] characteristics associated with resources. It provides the underlying foundation upon which digital asset management systems rely to provide fast, precise access to relevant resources across networks and between organizations.". In this sense, metadata is an "interface" to data (Schaffner, 2009).

Here, we discuss different metadata categories: social, contextual, competence, or domain-related metadata.

The recent focus on user-generated content and social web-communities leads to massive availability of social metadata: Content sharing and social bookmarking sites, weblogs and other publishing tools introduce tagging, annotation, rating, commenting, and discussion mechanisms, which can also be applied to educational resources. Skågeby (2009) lists different purposes for social metadata: sharing, recommendation, filtering, communication, or personal organisation of content. Usually, social metadata does not follow complex structures. The gathering mechanisms keep barriers low: simple rating scales or keyword input fields are all that is required.

Social metadata's quality depends on individual enthusiasts or the amount of users contributing. Recent standardisation approaches acknowldege the importance of social metadata: attention profile portability in the Attention Profile Markup Language (APML, http://www.apml.org/), or metrics of user participation in communities in the User Labor Markup Language (ULML, http://userlabor.org/).

Contextual information can be represented as context metadata to enable contextbased searching and filtering. Context comprises "conditions and circumstances 
PREPRINT Klemke, R., Ternier, S., Kalz, M. \& Specht, M. (2010). Implementing infrastructures for managing learning objects. British Journal of Educational Technology

relevant to an event, fact, etc." (Collins, 1999) or "interrelated circumstances in which something exists or occurs" (Webster's, 1996). "Context-aware" was introduced to describe mobile applications (Schilit and Theimer, 1994). What we define as context depends on what we contextualise (Klemke, 2000). Thus, "context is any information useful to characterize the situation of an entity. An entity is a person, place, or object considered relevant to the interaction between a user and an application, including the user and applications themselves. [...] A system is contextaware if it uses context to provide relevant information and/or services to the user." (Dey 2001).

Within MACE (Wolpers et al, 2009b), relevant entities to be contextualised are (1) architectural real world subjects and objects, (2) users, (3) digital contents describing (1) or (2). Within learning processes, important aspects of context are learning activities: MACE collects usage data in context metadata (Wolpers et al, 2009a) and enables context-based access to learning resouces.

To describe learning resources with competence metadata (related, required, or acquired), we need taxonomies of competences and scales describing possible mastery levels. Competence metadata for learning objects can be seen critically: while learning objects shall be fine-grained, reusable components, competence acquisition is a long-term process. An individual learning object's impact in this process is hard to measure.

Consequently, approaches to standardise competence models and educational ressources exist without proper integration: While HR-XML and IMS RDCEO allow to describe competencies, they focus on personal profiles rather then educational ressources (Sampson et al, 2007). Vice versa, LOM allows to describe educational ressources, but leaves out competence-related information. Recently, approaches extend existing metadata standards for educational resources with competence metadata (Sampson, 2009).

The impact of domain metadata on retrieval efficiency and accuracy may be low (Hawking and Zobel, 2007) especially in web information retrieval (Henshaw and Valauskas, 2001). Nevertheless, efforts to standardise and use domain metadata models range from controlled domain vocabulary towards semantic application profiles using ontology modelling techniques such as OWL (Koutsomitropoulos et al, 2007) leading to complex domain models as the CIDOC Conceptual Reference Model in cultural heritage (Crofts et al, 2003).

Domain metadata models have also been created in MACE and ICOPER. The benefit of a taxonomy of architectural terms in MACE is higher than in ICOPER, where standardised vocabulary can hardly be found for the broader "higher education" focus. The domain metadata model for ICOPER remains rather small. MACE evaluation shows that the effort pays off: "The evaluation of the MACE portal and subsequently of the MACE system clearly indicates that the targeted provision of learning resources increases the quality of results produced by university students." (Wolpers et al, 2009a).

Consequently, we state: domain metadata has an impact on retrieval efficiency and accuracy, if (a) the application domain is well defined and (b) the metadata is provided in high quality. 
PREPRINT Klemke, R., Ternier, S., Kalz, M. \& Specht, M. (2010). Implementing infrastructures for managing learning objects. British Journal of Educational Technology

\section{Metadata Generation}

This section looks at manual metadata creation by experts, authors, or end-users in contrast to automatic and combined metadata generation.

Professionally generated metadata is produced by librarians, catalogers, and others (Greenberg, 2002). In the digital age, metadata is generated for archives and repositories. Scientific and educational publishers organise their contents along standardised or proprietary metadata schemes. Generating metadata professionally is slow, expensive, and not scalable. It may be inappropriate in dynamic domains.

Authors are topic specialists - not metadata experts (Thomas and Griffin, 1998). Still, author generated metadata can be of high quality, given an understandable metadata schema like Dublin Core (Greenberg et al, 2001). Authors benefit from generating metadata: their resources become retrievable and reusable. However, among authors providing metadata for own ressources, common understanding lacks: authors produce inconsistent metadata.

Effort has been invested to create indexation forms to enter metadata. The ARIADNE foundation distinguished five categories of metadata ("General", "Semantics", "Pedagogical", "Technical" and "Indexation data"), serving as basis for IEEE LOM. LOM features around 80 metadata fields: automatically generated metadata lowers the effort a person has to invest.

Metadata can be generated from various sources. The Samgi framework (Cardinaels, Meire, and Duval, 2005) defines object and context based metadata extractors. Object based extractors generate metadata from resources directly: E.g. the JSTOR/Harvard Object Validation Environment (JHove, http://hul.harvard.edu/jhove) allows to generate metadata from file size, mime type, last modification date, etc. Contextual information about resources helps to generate metadata: consider a presentation uploaded to a course on "artificial intelligence" taught to bachelor students of computer science: context metadata can be inferred (e.g. classified under "computer science", target audience set to "higher education").

User generated metadata may be as useful as professional metadata for retrieval in some contexts (Melenhorst et al, 2008). Users providing metadata might not even know, what metadata is. Therefore, formal processes and complex taxonomies might fail to gather relevant metadata. Common techniques successfully circumvent this in various domains (e-shops, content sharing applications, community applications):

- Tags provide keyword annotations.

- Ratings reflect quality or appropriateness of contents via scales.

- Comments semantically annotate contents.

- Feedback-Forms gather semi-structured information using open/closed questions.

Despite usability-optimised tools, metadata creation involves effort. What motivates users? Personal benefit is important (e.g. the need to retrieve a resource again), but also reasons beyond: increasing the personal relevance of a resource (e.g. online bookmark application) or social benefits (like increased visibility). Hasan and Jameson (2008) state enjoyable experiences, successful task performance, and visible improvements to collections as motivational factors. However, metadata 
PREPRINT Klemke, R., Ternier, S., Kalz, M. \& Specht, M. (2010). Implementing infrastructures for managing learning objects. British Journal of Educational Technology

generated by users to organise resources for their own benefit varies from metadata generated with social purposes in mind (Bentley and Labelle, 2008).

User generated metadata approaches are scalable, cheap, and of reasonable quality. Nevertheless, unstructured vocabulary leads to conflicting or inappropriate use of terms. Cho and Tomkins (2007) list additional problems: vulnerability to spam and the locality of interest of users may lead to metadata, that is of little help to others.

Combined metadata generation can circumvent the disadvantages. Consider Wikipedia (http://www.wikipedia.org/): borders between automated, professional, or user-driven metadata generation disappear: users (ranging from specialists, enthusiasts to interested public) collaborativly develop ressources and provide metadata leading Wikipedia to become a well-knowned high quality ressource.

Obviously, some metadata fields are easy to generate automatically, others require manual activity (Spaniol et al, 2008). An evaluation of MACE, combining metadata generated by experts, user interactions, observation components and machinegenerated (Memmel, Schirru, Wolpers, and Tomadaki, 2008) shows, that this combination improves students performance in searching, retrieving, and using learning content (Wolpers et al, 2009a).

Combining different approaches increases complexity and amount of available metadata. Therefore, attractive, usable and intuitive user interfaces should simplify user interaction with metadata enriched content repositories (Zambelli et al., 2008). Figure 1 shows a visualisation of complex metadata for a learning content in MACE, comprising LOM metadata, geographical metadata, competence metadata, community metadata and a content preview.

$>>$ Figure $1<<<$

\section{Bringing contents into use}

This section looks at use cases to support learning with federated content:

1. Metadata-based content exploration: Exploring content spaces, supported by taxonomies/vocabularies of different metadata fields implicitly supports learners to familiarise with domain concepts and vocabularies.

2. Metadata visualisations enable reflection about exploration choices: users learn about number, types, and distribution of learning objects in a content federation. Visualising course-relevant competences can enhance reflection and communication between participants.

3. Metadata-based relations between learning objects: domain metadata enables learners to explore content in a non-curricular, explorative way. Displaying content-related concepts has been shown to efficiently enable learners to explore learning concepts and develop personal understandings (Kravcik et al, 2004). Interactive visualisations of relations such as the multi-touch MACE installation foster explorative browsing and visual comprehension (Zambelli et al. 2008).

4. Complex metadata queries: faceted filtering of learning objects enables users to interactively browse the content federation based on multiple metadata fields and to intuitively formulate complex queries while the metadata visualisation is adapted to the result set (Zambelli et al, 2008). 
PREPRINT Klemke, R., Ternier, S., Kalz, M. \& Specht, M. (2010). Implementing infrastructures for managing learning objects. British Journal of Educational Technology

5. Social exploration: social metadata informs learners about relations between content and community. Mirroring category and vocabulary usage gives guidance about user activities and quality of contributions.

6. Embedding of learning resources: Learning objects can be offered through dedicated portals or embedded in learning and working environments. The discussion about mashups and personal learning environments (Wild, Kalz, Palmer and Müller, 2009) contributes new requirements to the integration of learning objects into classical learning management systems (Wilson, Sharples, Griffiths and Popat, 2009) or personal learning environments where users mix and combine information resources from different sources.

In the last part of the paper we discuss lessons learned based on experiences from the projects discussed.

\section{Conclusion}

Managing metadata-based infrastructures to handle distributed repositories of learning objects helps to ease access to and reuse of vast amounts of online learning resources. In this article we have introduced several critical factors for infrastructures for federated learning obect repositories. We want to conclude by summarising the pitfalls and their respective avoidance strategy based on lessons learned in table 1.

$>>$ Table $1<<<$

\section{References}

Bentley, C. M., Labelle, P. R. (2008). A comparison of social tagging designs and user participation, Metadata for semantic and social applications: proceedings of the International Conference on Dublin Core and Metadata Applications - DC2008, Berlin, 22-26 September 2008.

Cardinaels, K., Meire, M., and Duval, E. (2005). Automating metadata generation: the simple indexing interface. Proceedings of the 14th international conference on World Wide Web, pages 548-556. ACM Press.

Cho, J., Tomkins, A. (2007). Guest Editors' Introduction: Social Media and Search. IEEE INTERNET COMPUTING, Vol. 11, 06, pp. 13-15.

Collins 1999. Collins English Dictionary, Millennium Edition, HarperCollins Publishers, Glasgow, 1999.

Crofts, N., Doerr, M. and Gill, T. (2003). The CIDOC Conceptual Reference Model: A standard for communicating cultural contents, Cultivate Interactive, issue 9, 7 February 2003.

Dey, A. K. (2001). Understanding and Using Context. Personal Ubiquitous Computing, Springer-Verlag. 5: 4-7.

Fielding, R. T. (2000). Architectural Styles and the Design of Network-based Software Architectures. PhD thesis, University of California, Irvine.

Greenberg, J., Pattuelli, M. C., Parsia B., Davenport Robertson, W. (2001) Authorgenerated Dublin Core Metadata for Web Resources: A Baseline Study in an Organization. Proc. Int'l. Conf. on Dublin Core and Metadata Applications DC2001, October 24-26, 2001, NII, Tokyo, Japan.

Greenberg, J. (2002) Metadata generation: Processes, people and tools. Bulletin of the American Society for Information Science and Technology, December 1, 2002. 
PREPRINT Klemke, R., Ternier, S., Kalz, M. \& Specht, M. (2010). Implementing infrastructures for managing learning objects. British Journal of Educational Technology

Hasan, T., Jameson, A. (2008). Bridging the Motivation Gap for Individual Annotators: What Can We Learn From Photo Annotation Systems? Proceedings of INSEMTIVE 2008, Workshop on Incentives for the Semantic Web, Karlsruhe, Germany, October 26th, 2008.

Hawking, D. \& Zobel, J. (2007). Does topic metadata help with web search? Journal of the American Society for Information Science and Technology. 58.5, 613-628.

Henshaw, R. \& Valauskas, E.J. (2001). Metadata as a catalyst: experiments with metadata and search engines in the Internet journal, First Monday. Libri. 51.2: 86-101.

Hunter, J. L. (2003). Working towards MetaUtopia - a survey of current metadata research. Library Trends, special issue: Organizing the Internet, 52(2).

IEEE LTSC (2002). Final Draft Standard for Learning Object Metadata. Retrieved 01/15/10 at http://ltsc.ieee.org/wg12/files/LOM_1484_12_1_v1_Final_Draft.pdf.

Klemke, R. (2000): Context Framework - an Open Approach to Enhance Organisational Memory Systems with Context Modelling Techniques, PAKM2000: Third International Conference on Practical Aspects of Knowledge Management, 2000, Basel, Switzerland.

Koutsomitropoulos, D. A., Paloukis, G. E., \& Papatheodorou, T. S. (2007). Semantic Application Profiles: A Means to Enhance Knowledge Discovery in Domain Metadata Models. Miguel-Angel Sicilia and Miltiadis D. Lytras (Eds.). Metadata and Semantics, Springer, ISBN 978-0-387-77744-3.

Kravcik, M., Specht, M. (2004). Flexible Navigation Support in the WINDS Learning Environment for Architecture and Design. Proceedings of Third International Conference, AH 2004, Eindhoven, The Netherlands, August 23-26, 2004, Lecture Notes in Computer Science, Vol. 3137, Nejdl, Wolfgang; De Bra, Paul (Eds.)

Lagoze, C. and Van de Sompel, H. (2001) The Open Archives Initiative: Building a Low-Barrier Interoperability Framework. Proc. 1st ACM/IEEE-CS Joint Conf. Digital Libraries, ACM Press, pp. 54-62.

Melenhorst, M., Grootveld, M., Veenstra, M., (2008). Tag-based informational retrieval for educational videos. EBU Technical Review, ISSN 1609-1469, 2008.

Memmel, M., Schirru, R., Wolpers, M. \& Tomadaki, E. (2008). Towards the Combined Use of Metadata to Improve the Learning Experience. Eighth IEEE International Conference on Advanced Learning Technologies, ICALT, pp.930-932.

Nejdl, W., Wolf, B., Qu, C., Decker, S., Sintek, M., Naeve, A., Nilsson, M., Palmér, M., and Risch, T. (2002). EDUTELLA: a P2P networking infrastructure based on RDF. WWW '02: Proceedings of the 11th International Conference on World Wide Web, pages 604-615, New York, NY, USA. ACM Press.

Sampson, D., Karampiperis, P., \& Fytros, D. (2007). Developing a Common Metadata Model for Competencies Description. Interactive Learning Environment, Special Issue on Learning Networks for Lifelong Competence Development, ISSN 10494820, vol. 15(2), pp. 137-150, Routledge.

Sampson, D. G. (2009). Competence-related Metadata for Educational Resources that Support Lifelong Competence Development Programmes. Educational Technology \& Society, 12 (4), 149-159.

Schaffner, J. (2009). The Metadata is the Interface: Better Description for Better Discovery of Archives and Special Collections. Synthesized from User Studies. OCLC Research. Dublin, Ohio: 2009. 
PREPRINT Klemke, R., Ternier, S., Kalz, M. \& Specht, M. (2010). Implementing infrastructures for managing learning objects. British Journal of Educational Technology

Schilit, B. N. \& M. Theimer, M. M. (1994). Disseminating Active Map Information to Mobile Hosts. IEEE Network. 8: 22-32.

Skågeby, J. (2009). Exploring Qualitative Sharing Practices of Social Metadata: Expanding the Attention Economy. The Information Society, 25 (1), January 2009, pp 60-72.

Simon, B., Massart, D., van Assche, F., Ternier, S., Duval, E., Brantner, S., Olmedilla, D. \& Miklós, Z. (2005) A Simple Query Interface for Interoperable Learning Repositories. Workshop on Interoperability of Web-Based Educational Systems in conjunction with 14th International World Wide Web Conference (WWW'05). May, Chiba, Japan.

Spaniol, M., Klamma, R., Lux, M., (2008). Imagesemantics: User-Generated Metadata, Content Based Retrieval \& Beyond. Journal of Universal Computer Science, 14 (10), 1792-1807.

Ternier, S., Vandepitte, P., \& Duval E. (2002). LOMster: Peer-to-peer Learning Object Metadata. Barker, P. and Rebelsky, S., editors, Proceedings of World Conference on Educational Multimedia, Hypermedia and Telecommunications 2002, pages 1942-1943, Denver, Colorado, USA. AACE.

Ternier, S., Massart, D., Van Assche, F., Smith, N., Simon, B. \& Duval, E. (2008). A Simple Publishing Interface For Learning Object Repositories. Proceedings of World Conference on Educational Multimedia, Hypermedia and Telecommunications 2008 (pp. 1840-1845). Chesapeake, VA: AACE.

Ternier, S.; Verbert K.; Parra, G.; Vandeputte, B.; Klerkx, J.; Duval, E.; Ordónez, V. and Ochoa, X. (2009) The Ariadne Infrastructure for Managing and Storing Metadata. Emerging E-Learning Technologies. IEEE Internet Computing, 13 (4), pp. 18-25, July/Aug. 2009.

Thomas C. \& Griffin, L. (1998) Who will create the Metadata for the Internet? First Monday: Peer Reviewed Journal of the Internet: 3 (12), http://firstmonday.org/htbin/cgiwrap/bin/ojs/index.php/fm/article/view/633/554

Webster. 1996. Webster's New Encyclopedic Dictionary, 1996.

Weibel, S., Kunze, J., Lagoze, C., and Wolf, M. (1998). Dublin core metadata for resource discovery. RFC 2413, Internet Engineering Task Force.

Wild, F., Kalz, M., Palmér, M., \& Müller, D. (Eds.). (2009). Mash-Up Personal Learning Environments. Proceedings of the 2nd Workshop MUPPLE'09. September, 29, 2009, Nice, France: CEUR Workshop Proceedings, online http://sunsite.informatik.rwth-aachen.de/Publications/CEUR-WS/Vol-506/.

Wilson, S., Blinco, K., \& Rehak, D. (2004). An e-Learning Framework. A summary. Alt-I-lab 2004 (Advanced Learning Technology Interoperability). JISC: Bristol, UK.

Wilson, S., Sharples, P., Griffiths, D., \& Popat, K. (2009). Moodle Wave: Reinventing the VLE using Widget technologies. In Wild, F., Kalz, M., Palmér, M., \& Müller, D. (Eds.). Mash-Up Personal Learning Environments. Proceedings of the 2nd Workshop MUPPLE'09. September, 29, 2009, Nice, France: CEUR Workshop Proceedings

Wolpers, M., Memmel, M., Giretti, A., (2009a). The MACE Experience - first evaluation results. Proceedings of Learning in the Synergy of Multiple Disciplines, 4th European Conference on Technology Enhanced Learning, EC-TEL 2009, Nice, France, September 29 - October 2, 2009, LNCS 5794.

Wolpers, M., Memmel, M., Klerkx, J., Parra, G., Vandeputte, B., Duval, E., Schirru, R., \& Niemann, K. (2009b). Bridging repositories to form the MACE experience. 
PREPRINT Klemke, R., Ternier, S., Kalz, M. \& Specht, M. (2010). Implementing infrastructures for managing learning objects. British Journal of Educational Technology

Journal on New Review of Information Networking (RINN), Edited by Leslie Carr, published by Taylor \& Francis Group, US, September 21, 2009.

Zambelli, M., Janowiak, A., Neuckermans, H. (Editors), 2008. Browsing architecture. Metadata and beyond. IRB Stuttgart (Germany), ISBN: 978-3-8167-7770-0, September 2008.

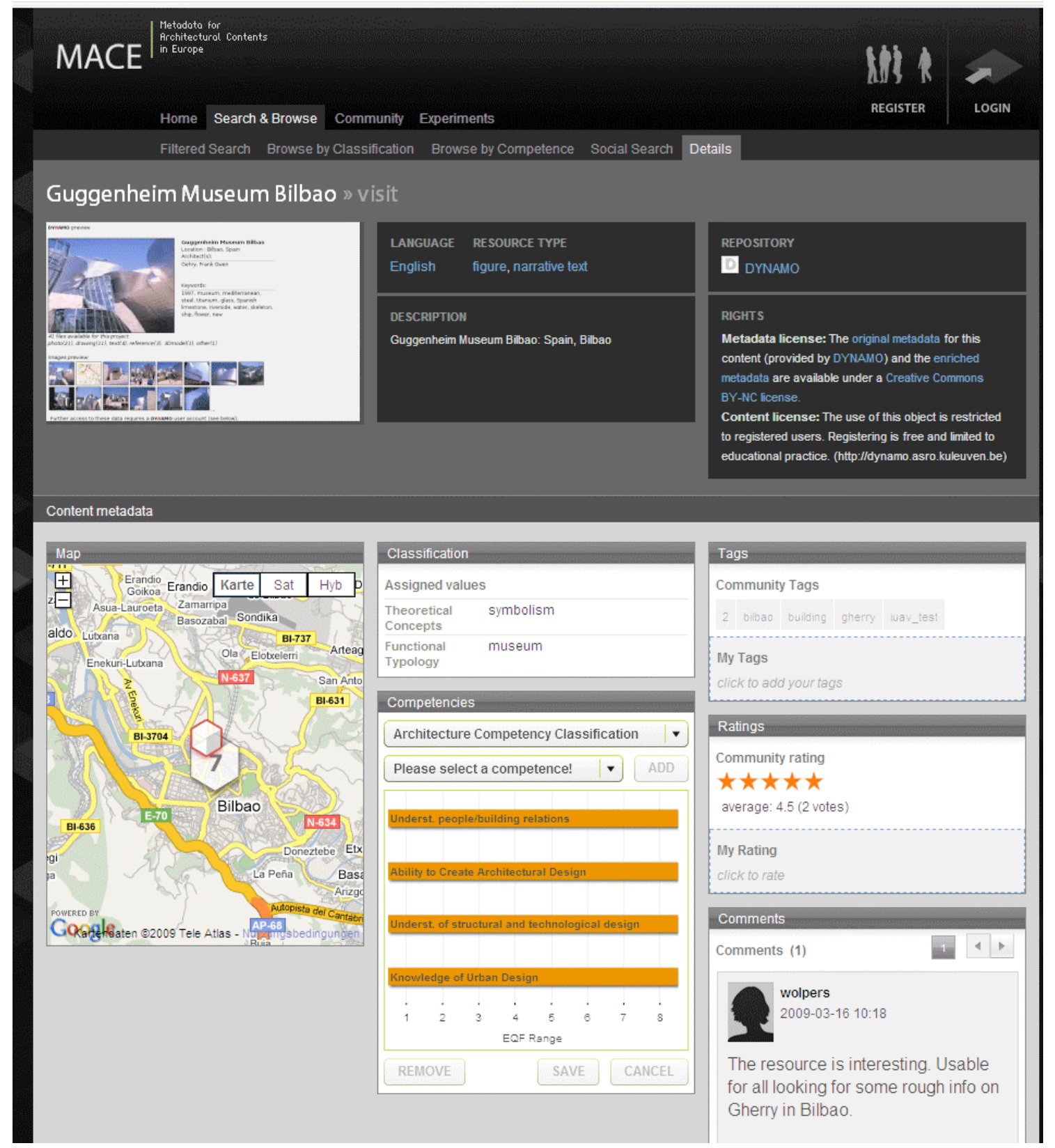

Figure 1: Metadata visualisation in MACE 
PREPRINT Klemke, R., Ternier, S., Kalz, M. \& Specht, M. (2010). Implementing infrastructures for managing learning objects. British Journal of Educational Technology

Table 1. Pitfalls and Strategies for Infrastructures for Learning Objects

\begin{tabular}{|c|c|c|}
\hline Aspect & Pitfall & Strategy \\
\hline $\begin{array}{l}\text { Distributed } \\
\text { content } \\
\text { management }\end{array}$ & $\begin{array}{l}\text { Keeping metadata distributed } \\
\text { across repositories (and } \\
\text { routing queries to the } \\
\text { repositories as originally done } \\
\text { in GLOBE) slows down search } \\
\text { applications, introduces } \\
\text { bottlenecks, and complicates } \\
\text { query language development } \\
\text { for heterogeneous repositories. }\end{array}$ & $\begin{array}{l}\text { By adopting harvesting based on } \\
\text { OAI-PMH, metadata is copied into } \\
\text { a central cache where it can be } \\
\text { queried efficiently. A drawback is } \\
\text { that search applications search in } \\
\text { stale data. However, when } \\
\text { repositories are (selectively) } \\
\text { harvested regularly, the delay } \\
\text { remains small. }\end{array}$ \\
\hline $\begin{array}{l}\text { Infrastructures } \\
\text { for content } \\
\text { federation }\end{array}$ & $\begin{array}{l}\text { The metadata application } \\
\text { profile (MAP) is critical, as it is } \\
\text { a backbone of the federation, } \\
\text { but its creation involves } \\
\text { complex political processes. } \\
\text { Changes to the MAP are quality } \\
\text { critical. }\end{array}$ & $\begin{array}{l}\text { Greatest care has to be taken in } \\
\text { designing the MAP with a focus } \\
\text { on areas that are likely to } \\
\text { change. }\end{array}$ \\
\hline $\begin{array}{l}\text { Classes of } \\
\text { Metadata }\end{array}$ & $\begin{array}{l}\text { Mistakes in selecting the } \\
\text { metadata structure can lead to } \\
\text { the non-acceptance of the } \\
\text { whole system. }\end{array}$ & $\begin{array}{l}\text { The choice of the metadata } \\
\text { structure has to reflect } \\
\text { usefulness, availability and the } \\
\text { possibility to generate new } \\
\text { metadata. Combining different } \\
\text { metadata categories is } \\
\text { promising: while creating } \\
\text { metadata, users can learn about } \\
\text { classification systems and } \\
\text { domain vocabularies. }\end{array}$ \\
\hline $\begin{array}{l}\text { Metadata } \\
\text { Generation }\end{array}$ & $\begin{array}{l}\text { Individual metadata generation } \\
\text { approaches may involve high } \\
\text { cost or effort, scale badly or } \\
\text { deliver incomplete/inaccurate } \\
\text { metadata. }\end{array}$ & $\begin{array}{l}\text { Combined metadata generation } \\
\text { approaches promise a good } \\
\text { balance between cost, } \\
\text { completeness, quality, and } \\
\text { quantity of generated metadata. }\end{array}$ \\
\hline $\begin{array}{l}\text { Bringing } \\
\text { contents into } \\
\text { use }\end{array}$ & $\begin{array}{l}\text { A badly designed user interface } \\
\text { is an obstacle to the use of a } \\
\text { metadata-based system. }\end{array}$ & $\begin{array}{l}\text { The user interface aspects of } \\
\text { metadata-based browsing, } \\
\text { searching and editing have to be } \\
\text { part of the system design from } \\
\text { the very beginning. }\end{array}$ \\
\hline
\end{tabular}

